\title{
DETECTION AND GENOTYPING Pasteurella multocida OF FIVE CAPSULAR GROUPS IN REAL TIME POLYMERASE CHAIN REACTION
}

\author{
A.V. NEFEDCHENKO' ${ }^{1}$, A.N. SHIKOV'2, A.G. GLOTOV', T.I. GLOTOVA', \\ V.A. TERNOVOY ${ }^{2}$, R.A. MAKSYUTOV ${ }^{1,2}$, A.P. AGAFONOV ${ }^{2}$, A.N. SERGEEV 2
}

\begin{abstract}
${ }^{1}$ Siberian Federal Scientific Centre of Agro-BioTechnologies RAS, Federal Agency of Scientific Organizations, p/b 463, r.p. Krasnoobsk, Novosibirsk Region, Novosibirsk Province, 630501 Russia, e-mail nav-vet@mail.ru, glotov_vet@mail.ru, t-glotova@mail.ru (corresponding author);

${ }^{2}$ State Research Center of Virology and Biotechnology Vector, Koltsovo, Novosibirsk Region, Novosibirsk Province, 630559 Russia, e-mail shikov_nsk@mail.ru, tern@vector.nsc.ru, agafonov@vector.nsc.ru, sergeev@vector.nsc.ru, maksyutov_ra@vector.nsc.ru
\end{abstract} ORCID:

Nefedchenko A.V. orcid.org/0000-0002-4181-4268 Shikov A.N. orcid.org/0000-0002-7051-6091 Glotov A.G. orcid.org/0000-0002-2006-0196 Glotova T.I. orcid.org/0000-0003-3538-8749 The authors declare no conflict of interests

Ternovoy V.A. orcid.org/0000-0003-1275-171X Maksyutov R.A. orcid.org/0000-0003-1314-281X Agafonov A.P. orcid.org/0000-0003-2577-0434 Sergeev A.N. orcid.org/0000-0001-7883-6017

Received May 30, 2016

\begin{abstract}
Respiratory diseases in calves cause significant economic losses in livestock. Bacterium Pasteurella multocida plays important role in the etiology of these diseases. It is known that five identified $P$. multocida capsular groups (A, B, D, E and F) differently affect animal epizooty. Identification of bacteria based on the cultural, morphological, biochemical properties is very laborintensive and time-consuming. Molecular biology techniques, in particular, the polymerase chain reaction (PCR), quickly detect and identify microorganisms directly in samples of biological material, mixed or pure cultures. In this regard, the purpose of our research was to develop multiplex realtime PCR for the detection, genotyping and discrimination of five P. multocida capsular groups (A, $\mathrm{B}, \mathrm{D}, \mathrm{E}$ and $\mathrm{F}$ ) in cattle. The target primers and probes to the highly conserved gene kmt 1 and the genes in the loci of capsule synthesis (hyaD, $f c b D, d c b F, b c b D$ and $e c b J)$ specific to the capsular groups have been designed. The sensitivity of DNA detection for different bacterial groups ranged from $1.6 \times 10$ to $5.9 \times 10^{2}$ genomic equivalents per reaction, non-specific reactions were not observed. The diagnostic sensitivity of the test was $10^{3} \mathrm{CFU} / \mathrm{ml}$ for pure cultures and $10^{5} \mathrm{CFU} / \mathrm{g}$ for biological material. The developed PCR protocol allowed us to type 11 bacterial cultures which were previously characterized serologically and bacteriologically and related to capsular groups A, B, and D. The kmt 1 gene sequencing confirmed the results of PCR analysis. PCR analysis of 260 samples from died calves detected $P$. multocida in lung $(63.3 \%)$, the lymph nodes $(42.6 \%)$, and spleen $(8.8 \%)$. We did not revealed the circulation of $P$. multocida B and E capsular groups among the tested livestock, the majority of the samples contained $P$. multocida group A, in some cases, there was group D, and, in one case, group $\mathrm{F}$.
\end{abstract}

Keywords: bacteria, Pasteurella multocida, real-time PCR, genes, capsular groups

Pasteurella multocida, a gram-negative, immobile, facultative anaerobic coccobacterium, is part of the commensal microflora of the upper respiratory tract of domestic and wild animals. The agent causes septic and respiratory diseases of cattle (with asignificant economic damage to livestock throughout the world [1-2], including in the Russian Federation [3-5]. The bacterium has five capsular groups (A, B, D, E, F) of different epizootological significance. The strains of capsular groups $\mathrm{A}$ and $\mathrm{D}$ are involved in respiratory diseases of calves and adult animals, B and $\mathrm{E}$ cause haemorrhagic septicemia in cattle and buffalo, and $\mathrm{F}$ is, though rarely, involved in septic and respiratory diseases of calves [6-8].

Microbiological identification based on the study of cultural and morphological and biochemical properties is a laborious and long-term process. Polymerase chain reaction (PCR) allows rapid detection and identification of microorganisms 
directly in samples of biological material, mixed or pure cultures [9].

To identify the bacterium and genotyping its capsule groups, several PCR-based test systems with electrophoretic detection [10-11] of different diagnostic efficacy have been developed [12]. Real-time PCR (PCR-RT) makes it possible to increase the reliability of diagnostic results due to elimination of contamination, as well as to quantify the target DNA in the sample being analyzed. One PCR-RT protocol is currently described for the detection of the sequence of the est gene in P. multocida serotypes B:2 and E:2 associated with hemorrhagic septicemia of cattle [13]. This technique is based on the use of the intercalating dye SYBR Green which, however, does not allows to differentiate the capsular groups of the bacterium.

Data on the nucleotide sequence of the second region in the locus for synthesis of $P$. multocida capsule allowed identifying unique genes for each capsular group which encode proteins involved in the synthesis of group-specific capsular polysaccharides. The hyaD gene is responsible for synthesis of hyaluronic acid and is unique for group A strains, $f c b D$ encodes chondroitin synthase in group $\mathrm{F}, d c b F$ is responsible for synthesis of heparan glycoside in D. Genes $b c b D$ and $e c b J$ encode glycosyltransferase in strains of capsular groups B and E, respectively. Also cell wall protein gene kmtl highly conserved and unique for the P. multocida [14] is identified.

We first designed the primers and TaqMan probes which allow us to identify and genotype serogroups of $P$. multocida in a multiplex PCR with realtime detection with high specificity and sensitivity.

The purpose of our research was to develop a rapid and highly sensitive method for detection of Pasteurella multocida and genotyping its five capsular groups in bacterial suspensions and samples from sick animals.

Techniqur. Reference strains of P. multocida (1231, 681 and T80), as well as Mannheimia haemolytica (strain 16), obtained from the collection of Ya.R. Kovalenko All-Russian Research Institute of Experimental Veterinary (Moscow). Other cultures of $P$. multocida were isolated in the Siberian Federal Scientific Center for Agrobiotechnology RAS in 2013-2014.

A total of 260 samples of lungs, spleen, mediastinal and bronchial lymph nodes served as biomaterials. For study, $10 \%$ suspensions were prepared. Samples were collected from six large dairy complexes in the Tyumen, Novosibirsk and Krasnoyarsk regions from Holstein-Frisian dead calves (aged from 4 days to 3 months) with signs of respiratory infection. Calves were kept in individual houses or cages at temperatures from -5 to $-9{ }^{\circ} \mathrm{C}$ (cold method). Feeding and husbandry were consistent with physiological and zootechnical standards.

DNA from bacterial suspensions and tissue samples was isolated using the commercial Ribo-prep kit (Central Research Institute of Epidemiology, Russia).

Specific primers and probes were designed in Vector NTI 9.0.0 (InforMax, Inc., USA) using the kmt 1 and cap locus gene sequences of $P$. multocida bacteria (capsule groups A, B, D, E, F) deposited in GenBank (NCBI).

The amplification was carried out in real time PCR in a $30 \mu$ reaction mixture containing $5 \mu \mathrm{l}$ of the DNA template, $1 \times$ Taq buffer without $\mathrm{Mg}^{2+}$ (OOO Medigene Laboratory, Russia), $3.3 \mathrm{mM} \mathrm{MgCl} 2,0.2 \mathrm{mM}$ dNTP, $150 \mathrm{nM}$ of each primer, $200 \mathrm{nM}$ of each probe, 1.5 U SmartTaq DNA polymerase (OOO Medigene Laboratory, Russia) and sterile deionized water. The protocol: $5 \mathrm{~min}$ at $95{ }^{\circ} \mathrm{C} ; 15 \mathrm{~s}$ at $94{ }^{\circ} \mathrm{C}, 20 \mathrm{~s}$ at $53{ }^{\circ} \mathrm{C}, 20 \mathrm{~s}$ at $72{ }^{\circ} \mathrm{C}(45$ cycles $)$ on a CFX96 amplifiers (Bio-Rad, USA); the detection channels was FAM/Green, ROX/Orange, Cy5/Red and R6G/Yellow at a cycling of $53{ }^{\circ} \mathrm{C}$.

Positive control samples (PCS) were obtained by molecular transformation of Escherichia coli (Top 10 strain) with plasmids pCR $^{\circledR} 2.1$ (Invitrogen, USA) 
containing specific DNA inserts of amplified bacterial genes. Synthetic fragments of DNA were used as DNA inserts specific for $P$. multocida capsule groups E and F. The plasmid DNA concentration was measured with Quant-iT dsDNA, HS reagent kit (Invitrogen, USA) on a QUBIT fluorimeter (Invitrogen, USA).

The analytical sensitivity of the method was evaluated separately for each determination. The diagnostic sensitivity of the method was established using 10fold dilutions of $P$. multocida (CP-57, 681, MSC-13) cultures, the concentration of which was previously determined by standard bacteriological methods. The sensitivity of the PCR was evaluated with tissue material. For this, $100 \mu \mathrm{l}$ of bacterial culture was added to $900 \mu \mathrm{l}$ of a $10 \%$ suspension of the lung or lymph node, mixed, sedimented, and the upper aqueous phase was examined. The number of bacteria was expressed as CFU per gram of tissue. DNA from the samples was isolated as described above.

To confirm the specificity of the reaction, the amplified gene fragments were sequenced using BigDye ${ }^{\circledR}$ Terminator v3.1 Cycle Sequencing Kits (Applied Biosystems, USA). The products were analyzed by capillary electrophoresis in an automatic sequencer ABI PRISM ${ }^{\circledR}$ 3130xl (Applied Biosystems, USA).

Results. In PCR, using all the primers and probes developed by us (Table 1), all the studied reference strains and $P$. multocida cultures were identified without nonspecific reaction (Table 2).

1. Sequences of primers and fluorescently labeled probes for detection of Pasteurella multocida and genotyping of its capsule groups

\begin{tabular}{|c|c|c|c|c|}
\hline Target gene & 兽 & Sequence $\left(5^{\prime} \rightarrow 3^{\prime}\right)$ & Position & 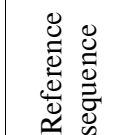 \\
\hline \multicolumn{5}{|c|}{ First reaction } \\
\hline kmt1 & P.m.-Kmtl F & ATAAGAAACGTAACTCAACATGGAAATA & 266-292 & \multirow[t]{3}{*}{ FJ986389 } \\
\hline (Pasteurella & P.m.-Kmtl R & GAGTGGGCTTGTCGGTAGTCTT & 456-477 & \\
\hline multocida) & P.m.-Kmt1 Z & (FAM)-AAACCGGCAAATAACAATAAGCTGA-(BHQ1) & $322-346$ & \\
\hline hyaD & P.m.-A F & TTCGTTAAAAATGACAGCTATGC & $9165-9187$ & \multirow[t]{3}{*}{ AF067175 } \\
\hline (capsular & P.m.-A R & ATAATCGTCAGAAGCTCATGCG & $9388-9367$ & \\
\hline group A) & P.m.-A Z & (R6G)-ATTTCTCAGCATTAACACATGATTGGAT- (BHQ1) & $9217-9244$ & \\
\hline$d c b F$ & P.m.-D F & ATCGCATCCAGAATAGCAAACTC & $3306-3328$ & \multirow[t]{2}{*}{ AF302465 } \\
\hline (капсульная & P.m.-D R & TCCGATGCTTTGGTTGTGC & $3661-3643$ & \\
\hline $\begin{array}{l}\text { capsular } \\
\text { group D) }\end{array}$ & P.m.-D Z & $\begin{array}{l}\text { (Cy5)-CCGATTAAACTCAAATCTAGGGACATACTT- } \\
\text { (BHQ2) }\end{array}$ & $3350-3379$ & \\
\hline \multicolumn{5}{|c|}{ Second reaction } \\
\hline$b c b D$ & P.m.-B F & GCGTGTATAACCTACATCTTCCCA & $12541-12564$ & \multirow{3}{*}{$\begin{array}{ll}4 & \text { AF169324 } \\
7 & \end{array}$} \\
\hline (capsular & P.m.-B R & CGTCCATCAACACCTTTACTGC & $12708-12687$ & \\
\hline group B) & P.m.-B Z & (FAM)-TAGGCACAGAATATTCAAAACCCCGT-(BHQ1) & $12618-12643$ & \\
\hline ecbJ (capsular & P.m.-E F & TGGGCACATGCTCGCTTA & 4539-4556 & \multirow{2}{*}{ AF302466 } \\
\hline group E) & P.m.-E R & CTGCTTGATTTTGTCTTTCTCCTAA & 4896-4872 & \\
\hline & P.m.-E Z & (ROX)-ATGTGGCAAAGCGATCAATTCAGA-(BHQ2) & $4631-4654$ & \\
\hline$f c b D$ (capsular & P.m.-F F & CGGAGAACGCAGAAATCAGAA & $2885-2905$ & \multirow[t]{2}{*}{ AF302467 } \\
\hline group F) & P.m.-F R & CAACAACGACTTCAAATGGGTAG & $3142-3120$ & \\
\hline & P.m.-F Z & (R6G)-CTTGCTCCATTGCCAGATCATGTT-(BHQ1) & $2947-2970$ & \\
\hline
\end{tabular}

The results of capsular genotyping of bacterial cultures (see Table 2) coincided with the data obtained in previous studies [15]. Analysis of the nucleotide sequences of the kmt1 gene amplicons in the cultures showed 99-100\% identity with fragments of the P. multocida gene form GenBank (KP212385, KP212386, KP212387, KP212388, KP212389, KP212390, KP212391).

The analytical sensitivity of the test was the last PCS dilution in which the PCR result was interpreted as positive. Samples with $\mathrm{Ct}$ not exceeding 40 were considered positive. Thus, the analytical sensitivity of the method was from $1.6 \times 10$ to $5.9 \times 10^{2}$ genomic equivalents (GE) per reaction (Fig.). 


\section{Bacterial cultures used in the work, and the results of their genotyping}

\begin{tabular}{|c|c|c|c|c|}
\hline \multirow{2}{*}{ Type of bacteria } & \multirow{2}{*}{ Strain } & \multirow{2}{*}{ Origin } & \multicolumn{2}{|c|}{ PCR test } \\
\hline & & & P. multocida & P. multocida \\
\hline \multirow{3}{*}{$\overline{\text { Pasteurella multocida }}$} & 1231 & Collection of microorganism cultures & + & $\mathrm{A}$ \\
\hline & 681 & of the Ya.R. Kovalenko All-Russian & + & $\mathrm{B}$ \\
\hline & $\mathrm{T}-80$ & Research Institute of & + & B \\
\hline Mannheimia haemolytica & 16 & Experimental Veterinary & - & \\
\hline Escherichia coli & F-50 & & - & \\
\hline \multirow[t]{9}{*}{ P. multocida } & $\mathrm{T}-14$ & Collection of the Siberian Federal & + & A \\
\hline & MSC-13 & Scientific Center for Agrobiotechnolo- & + & $\mathrm{D}$ \\
\hline & Sib-13 & gy RAS & + & A \\
\hline & Omsk-13 & & + & A \\
\hline & UK-59 & & + & A \\
\hline & SR-57 & & + & A \\
\hline & AGM/2013 & & + & A \\
\hline & OB-58 & & + & A \\
\hline & $\mathrm{T}-14$ & & + & A \\
\hline \multirow[t]{2}{*}{ Mannheimia haemolytica } & Sib-13 & & - & \\
\hline & Omsk-13 & & - & \\
\hline Streptococcus pneumoniae & UK-59 & & - & \\
\hline Clostridium perfringens & SR-57 & & - & \\
\hline Klebsiella pneumoniae & AGM/2013 & & - & \\
\hline Salmonella typhimurium & OB-58 & & - & \\
\hline \multicolumn{2}{|c|}{ Salmonella paratyphimurium } & & - & \\
\hline Note. "+" and "-" mean & positive and & negative result, respectiely. & & \\
\hline
\end{tabular}
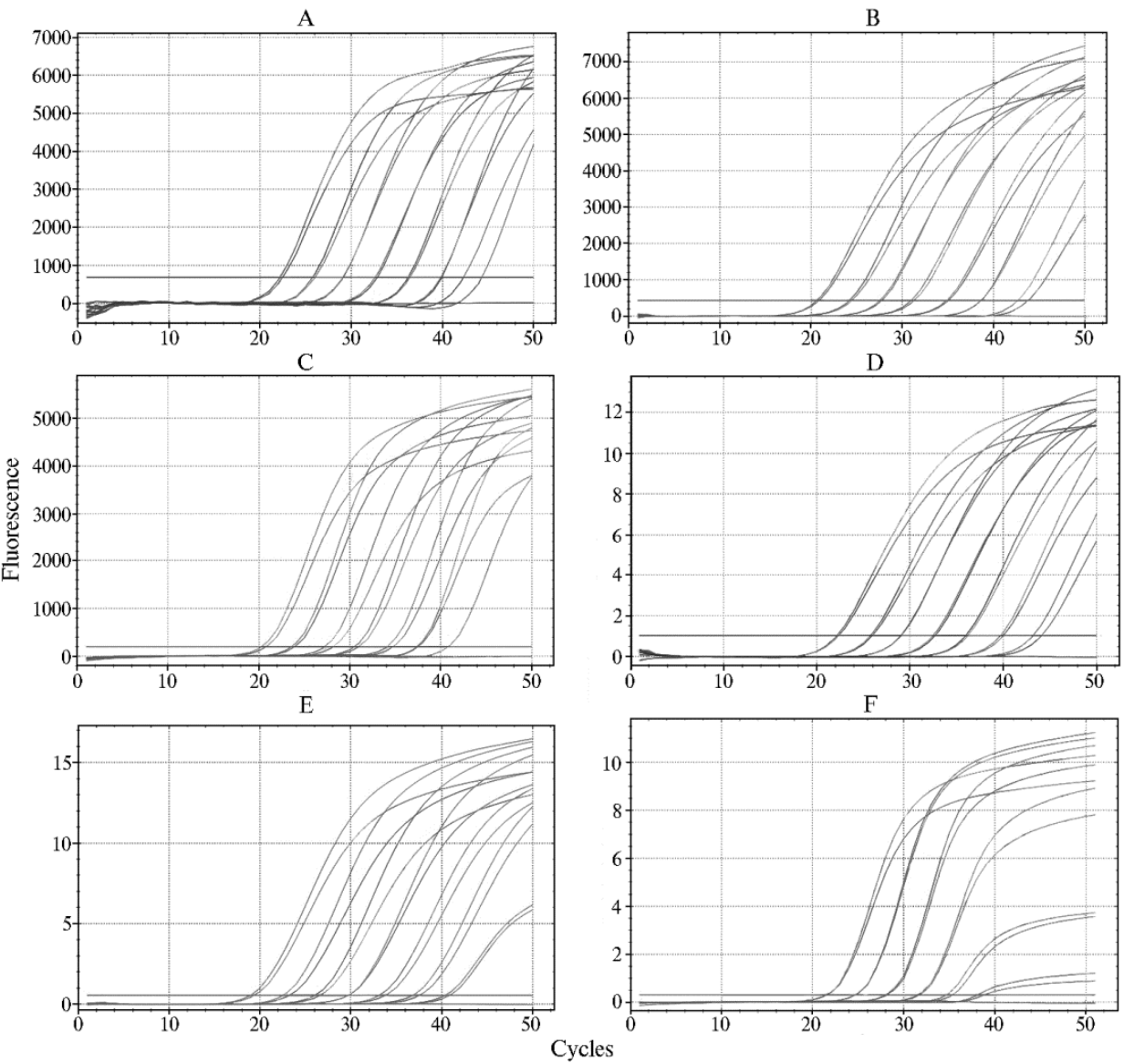

Evaluation of the analytical sensitivity of the test system using dilutions of positive control samples (PCS) obtained by molecular transformation of Escherichia coli (strain Top 10) with plasmids pCR ${ }^{\circledR}$ 2.1: A - fluorescence of PCS/P.m.-Kmt1 samples, FAM/Green channel; B - fluorescence of PCS/P.m.-A samples, R6G/Yellow channel; C - fluorescence of the PCS/P.m.-D samples, the Cy5/Red channel; D - fluorescence of PCS/P.m.-B samples, FAM/Green channel; E - fluorescence of PCS/P.m.-E samples, ROX/Orange channel; F - fluorescence of PCS/P.m.-F samples, 
R6G/Yellow channel. PCR and recording were performed on a CFX96 thermocycler (Bio-Rad, USA). Experiments were carried out in duplicate. Analytical sensitivity (in genomic equivalents per reaction) was $1.6 \times 10$ for PCS/P.m.-Kmt1, $7.2 \times 10$ for PCS/P.m.-A, $1.5 \times 10^{2}$ for PSC/P.m.-D, $9.0 \times 10$ for PCS/P.m.-B, $8.1 \times 10$ for PCS/P.m.-E, and $5.9 \times 10^{2}$ PCS/P.m.-F.

In the test, the primers and probes revealed $P$. multocida with the same efficiency and allowed genotyping capsular groups A, B and D. The diagnostic sensitivity of the test was $10^{3} \mathrm{CFU} / \mathrm{ml}$ for bacterial suspension, and $10^{5} \mathrm{CFU} / 1$ $\mathrm{g}$ for the tissue samples.

3. Detection of Pasteurella multocida and genotyping of its capsule groups in organs form deid Holstein-Frisian calves

\begin{tabular}{l|c|c|c|c|c}
\hline \multirow{2}{*}{ Biomaterial } & \multirow{2}{*}{ Number of samples } & \multirow{2}{*}{ Detection } & \multicolumn{3}{c}{ Capsular group } \\
\cline { 4 - 6 } & & & $\mathrm{A}$ & $\mathrm{D}$ & $\mathrm{F}$ \\
\hline Lungs & 161 & $102 / 63.3$ & $89 / 88.2$ & $12 / 10.8$ & $1 / 0.9$ \\
Lymph nodes & 54 & $24 / 42.6$ & $20 / 86.9$ & $3 / 13.0$ & $1 / 4.3$ \\
Spleen & 45 & $4 / 8.8$ & $3 / 75.0$ & 0 & $1 / 25.0$ \\
$\quad$ Total & 260 & $130 / 50.0$ & $112 / 86.2$ & $15 / 11.5$ & $3 / 2.1$ \\
\hline
\end{tabular}

N o t e. The number of positive samples and the percentage of samples examined (detection) or those in which $P$. multocida DNA was detected (capsule groups) are Before and after slashes, respectively.

The developed PCR protocol was used to analyze samples of biological material from sick animals. The genome of $P$. multocida was detected in $63.3 \%$ lung samples, $42.6 \%$ lymph nodes, and $8.8 \%$ spleen tissue (Table 3). P. multocida genotype A was in $82.6 \%$ of positive samples, genotype D in $11.5 \%$, and genotype $\mathrm{F}$ in three samples $(2.1 \%)$. More frequent detection of capsular group A indicates that it played a more important epizootic role in the surveyed farms than the strains of the capsular group D. In one animal, the P. multocida bacterium of the capsular group $\mathrm{F}$ was genotyped in three samples. The circulation of genotypes B and E among susceptible animals has not been established.

Thus, we developed a method for the detection and genotyping of five capsule groups (A, B, D, E, F) of Pasteurella multocida in real-time PCR. The proposed method is high specific and sensitive when testing bacterial cultures and biological material from sick animals. Bacteria of capsular group A were found in the largest number of samples. The developed PCR protocol can be used in veterinary diagnostic laboratories as a simple, accessible and easily reproducible analog of serological typing, which allows to detect the $P$. multocida bacterium and to genotype five of its capsular groups at all stages of bacteriological studies. The use of RT-PCR will shorten the diagnosis and allow to optimize anti-epizootic measures, in particular vaccine selection and the development of a highly effective program for the prophylactic immunization.

\section{REFEREN C ES}

1. Dabo S.M., Taylor J.D., Confer A.W. Pasteurella multocida and bovine respiratory disease. Anim. Health. Res. Rev., 2007, 8(2): 129-150 (doi: 10.1017/S1466252307001399).

2. Ri m le r R.B., R ho a d e s.R. Pasteurella multocida. In: Pasteurella and pasteurellosis. C. Adlam, J.M. Rutter (eds.). Academic Press Limited, London, 1989.

3. Glotov A.G., Petrova O.G., Glotova T.I., Nefedchenko A.V., Tatarchuk A.T., Koten eva S.V., Vetrov G.V., S e rge ev A.N. Veterinariya, 2002, 3: 1721. Available http://elibrary.ru/item.asp?id=22435011. No date (in Russ.).

4. Glotov A.G., Glotova T.I., Nefedchenko A.V., Koteneva S.V., Budulo v N.R., Ku ngurts e v O.V. Sibirskii vestnik sel'skokhozyaistvennoi nauki, 2008, 3: 72-78. Available http://elibrary.ru/item.asp?id=9899939. No date (in Russ.).

5. Shibaev M.A., Dudnikov S.A., Prokhvatilova L.B. Veterinarnaya patologiya, 2009, 4: 50-55. Available http://elibrary.ru/item.asp?id=16769773. No date (in Russ.).

6. Taylor J.D., Fult on R.W., D abo S.M., Le he nbaue r T.W., Confer A.W. Comparison of genotypic and phenotypic characterization methods for Pasteurella multocida isolates from fatal cases of bovine respiratory disease. J. Vet. Diagn. Invest., 2010, 22(3): 366-375 (doi: $10.1177 / 104063871002200304)$. 
7. Wilki e I.W., Harper M., B oy ce J.D., Adle r B. Pasteurella multocida: diseases and pathogenesis. Curr. Top. Microbiol. Immunol., 2012, 361: 1-22 (doi: 10.1007/82_2012_216).

8. Haemorrhagic septicaemia, Chapter 2.4.12. In: Manual of diagnostic tests and vaccines for terrestrial animals. 7 Edition. OIE, 2012: 732-744.

9. Te re nt ye va T.E., G lot ova T.I., G lotov A.G., D o n c he n k o N.A. Sibirskii vestnik sel'skokhozyaistvennoi nauki, 2014, 3: 90-95. Available http://elibrary.ru/item.asp?id=21732890. No date (in Russ.).

10. Townsend K.M., Frost A.J., Le e C.W., Papadimitrious J.M., Dawkins H.J. Development of PCR assays for species and type specific identification of Pasteurella multocida isolates. J. Clin. Microbiol., 1998, 36(4): 1096-1100.

11. D ziva F., M uhai rwa A., B is ga a rd M., C h ristense $\mathrm{n} \mathrm{H.} \mathrm{Diagnostic} \mathrm{and} \mathrm{typing}$ options for investigating diseases associated with Pasteurella multocida. Vet. Microbiol., 2008, 128(1-2): 1-22 (doi: 10.1016/j.vetmic.2007.10.018).

12. Adhikary S., B isga ard M., Foster G., Kiessling N., Fahlén A.R., Ols e $\mathrm{n}$ J.E., Ch riste n s e n H. Comparative study of PCR methods to detect Pasteurella multocida. Berl. Munch. Tierarztl. Wochenschr., 2013, 126(9-10): 415-22.

13. Pet e rsen A., B isga ard M., Townsend K., Christensen H. MLST typing of Pasteurella multocida associated with hemorrhagic septicemia and development of a real-time PCR specific for hemorrhagic septicemia associated isolates. Vet. Microbiol., 2014, 170(3-4): 335-341 (doi: 10.1016/j.vetmic.2014.02.022).

14. Townse nd K.M., B oyce J.D., Chung J.Y., Frost A.J., Ad ler B. Genetic organization of Pasteurella multocida cap loci and development of a multiplex capsular PCR typing system. J. Clin. Microbiol., 2001, 39(3): 924-929 (doi: 10.1128/JCM.39.3.924-929.2001).

15. Glotov A.G., G lotova T.I., Nefed chenko A.V., Terentyeva T.E. Sibirskii vestnik sel'skokhozyaistvennoi nauki, 2013, 2: 88-93. Available http://elibrary.ru/item.asp?id=19080328. No date (in Russ.). 